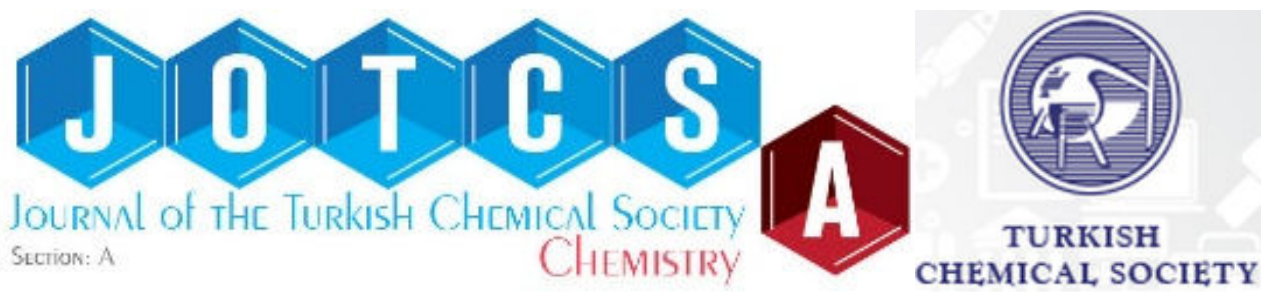

\title{
Determination of Cd(II) Ions by using Cyclodextrin-Based Polymeric Fluorescence Sensor
}

\author{
Soner ÇUBUK* , Özge YILMAZ, Ece KÖK YETIMOĞLU, Memet Vezir KAHRAMAN \\ Marmara University, Faculty of Arts and Sciences, Chemistry Department, 34722 \\ Istanbul, Turkey
}

\begin{abstract}
In this study, Cd(II) ion was determined using a cyclodextrin-based polymeric fluorescence sensor prepared by UV-curing technique. The effects of several parameters such as $\mathrm{pH}$, time, and coexisting ions on the fluorescence intensity were also examined. The excitation and emission wavelengths were found to be $374 \mathrm{~nm}$ and $422 \mathrm{~nm}$, respectively. The measurement range was in the range of $4.45 \times 10^{-9} \mathrm{~mol} \mathrm{~L}^{-1}$ to $4.45 \times 10^{-8}$ mol $\mathrm{L}^{-1}$ for $\mathrm{Cd}(\mathrm{II})$ ions and the detection limit was calculated as $6.23 \times 10^{-10} \mathrm{~mol} \mathrm{~L}^{-1}$. In addition, sensor membrane was selective which was not influenced by common coexisting metal ions. The concentrations of the foreign ions such as $\mathrm{Pb}$ (II), $\mathrm{Co}$ (III), $\mathrm{Ag}$ (I), $\mathrm{Zn}$ (II), $\mathrm{Cu}(\mathrm{II}), \mathrm{Cr}$ (III) are 1000-fold higher than $\mathrm{Cd}(\mathrm{II})$ ions. Besides the prepared polymeric fluorescence sensor was successfully implemented to the determination of $\mathrm{Cd}$ (II) ions in biscuit and tap water samples.
\end{abstract}

Keywords: Fluorescence sensor; photopolymerization; Cd(II) ions.

Cite this: Cubuk S, Yilmaz O, Kok Yetimoglu E, Kahraman M. Determination of Cd(II) Ions by using Cyclodextrin-Based Polymeric Fluorescence Sensor. JOTCSA.

2017;4(2):61-72.

Submitted: February 13, 2017. Accepted: March 23, 2017.

DOI: $10.18596 /$ jotcsa.292001.

Corresponding author: Soner Çubuk; sonercubuk@marmara.edu.tr 


\section{INTRODUCTION}

The rapid spread of industrialization in the world, the emergence of new technologies, urbanization that has been continuously distorted due to the growing population around cities and villages and the attempt is made to provide all the requirements attached to them and the consumption of excessive quantities of chemical substances, including heavy metals, are closely related. Cadmium is among the heavy metals that cause environmental pollution today and it affects human life with ways such as cigarette smoke, refined foodstuff, water pipes, coffee, tea, shellfish, coal burning, and fertilizers. In addition, cadmium is used in coating industry, solar batteries, plastic stabilizers, and dye and pigment industries. Cadmium compounds can be released to the atmosphere through the metallurgical process or when the metal is removed by heating from its ore. Cadmium passes through the ground through the rain and accumulates at the same time. It moves through the layers of soil and enters the food chain, primarily through grains and vegetables. Cadmium enters the human body through contaminated food and water. It is quite poisonous, even at low concentrations, and causes damage to organs such as the liver, lungs, and kidneys with vital importance in the human body through bioaccumulation and it also increases the risk of getting some types of cancer, such as prostate and breast, as a result of toxic effects. Moreover, exposure to cadmium significantly affects the basic systems of our body such as digestion, respiration, lymph and blood circulatory, and urinary. Therefore, the level of cadmium in various matrices, such as food and water, especially in drinking water sources, must be constantly monitored and analyzed (1-3).

The determination of cadmium, which has such great effects on human health and environment, has become very important nowadays. For this reason, many methods including differential pulse anodic stripping voltammetry (DPASV) (4, 5), flame atomic absorption spectrometry (FAAS) (6), inductively coupled plasma optical emission spectrometry (ICP-OES) (7), potentiometry (8-9), spectrofluorimetry $(10,11)$, spectrophotometry $(12,13)$ and inductively coupled plasma atomic emission spectroscopy (ICP-AES) (14) have been developed. These methods can provide wide linear range values and good detection limits, but they need to use very expensive devices in the laboratory and a qualified staff for the application. However, spectrofluorometric methods have many advantages over sophisticated methods such as cost, fast response time, high precision. Considering the disadvantages of conventional methods, there is no doubt that alternative methods of cadmium ions detection will be needed instead of these methods and fluorescence methods will be important for cadmium ions determination. 
In our study, reusable $\beta$-cyclodextrin ( $\beta-C D$ ) based polymeric fluorescent sensor has been developed that provides sensitive, precise, fast and reproducible results for the determination of $\mathrm{Cd}$ (II) ions. Once the characterization of the sensor has been made, optimal conditions have been determined so that the analysis can be performed.

\section{MATERIALS AND METHODS}

\section{Chemicals}

In this study, all of the monomers and other chemical substances used in the preparation of the polymeric membrane were obtained from Sigma and all the these were of analytical purity. All stock single metal solutions with a concentration of $1000 \mathrm{ppm}$ were purchased from Merck Millipore. The working solutions of the metals used in the experiments were also prepared by diluting these stock solutions with distilled water to reach the desired concentrations.

\section{Instrumentation}

A Varian Cary Eclipse spectrofluorometer was used to record excitation and emission spectra. The $\mathrm{Cd}$ (II) ion concentration in real samples was analyzed by FAAS so that the results could be compared with the developed method. A Perkin Elmer Spectrum 100 spectrophotometer was used and ATR-FTIR spectrum of membrane and identify the surface of membrane was carried out by a Philips XL30 ESEM-FEG/EDAX scanning electron microscope. The results obtained from the Perkin Elmer AAnalyst 700 graphite furnace atomic absorption spectrophotometer (GF-AAS) were used to compare the $\mathrm{Cd}$ (II) concentrations of the real samples with those obtained by the developed method.

\section{Method}

Synthesis of the $\beta$-cyclodextrin acrylate $(\beta-C D-A)$ monomer

The $\beta-C D-A$ were synthesized following reported procedure by Constantin et. al (15). For the synthesis of the functional $\beta-C D-A$ monomer, $11.38 \mathrm{~g}$ of $\beta-C D$ was weighed in a threeneck round-bottom flask. Then $30 \mathrm{~mL}$ of dimethyl formamide (DMF) was added and dissolved at $50{ }^{\circ} \mathrm{C}$ and $12 \mathrm{~g}$ of trimethylamine (TEA) was added. Then $50 \mathrm{~mL}$ of DMF solution containing $10.8 \mathrm{~g}$ of acryloyl chloride (AC) was added dropwise to the reaction flask over 2 hours. At the end of the time, the reaction was stopped and flask content was filtered through the filter paper. All the filtrate was then poured dropwise onto cold acetone to obtain white precipitates. The precipitate was left to dry overnight in the lyophilizer. 


\section{Preparation of polymeric sensor}

Polymeric sensor was prepared by UV-curing technique. The $\beta-C D-A$ and 2-hydroxy-2methylpropiophenone (HMPP) were used as a reactive monomer and as a photoinitiator, respectively. For preparation of the membrane, $1 \% \beta-C D-A, 25 \%$ 2-hydroxyethyl methacrylate (HEMA), 74\% hexanedioldiacrylate (HDDA) and $3 \%$ of total formulation HMPP were placed in a beaker and then homogenized by mixing. The resulting mixture was transferred to a mold having dimensions of $12 \mathrm{~mm} \times 40 \mathrm{~mm} \times 2 \mathrm{~mm}$ and UV light (OSRAM $300 \mathrm{~W}, \lambda_{\max }=365 \mathrm{~nm}$ ) was applied for 3 minutes. The membranes obtained at the end of the period were removed from the matrix and allowed to stand in distilled water for 24 hours to remove the excess of unreacted monomers and initiator. Then the membranes were dried in a lyophilizer.

\section{Preparation of real samples}

In order to validate the developed method, two different real sample analyzes were performed for $\mathrm{Cd}$ (II) ions. One of them was biscuit as a food sample and the other was tap water. Biscuit samples were purchased from public market and tap water samples were collected from the consumer's tap. Microwave assisted acid digestion method was used for digestion of biscuit samples. These samples were prepared for analysis according to BS EN 13804:2013 method (16). The concentrations of $\mathrm{Cd}(\mathrm{II})$ ions in the solutions were measured by a developed sensor and GF-AAS method.

\section{RESULTS AND DISCUSSION}

\section{Characterization}

The ATR-FTIR spectrum of polymeric membrane obtained by scanning at a wavenumber between $400-4000 \mathrm{~cm}^{-1}$ is shown in Figure 1 . Typical $\mathrm{O}-\mathrm{H}$ vibrations in $\beta-\mathrm{CD}$ and HEMA structures seen in the spectrum are observed at $3384 \mathrm{~cm}^{-1}$. The peaks corresponding to the C-O stretching vibration appear at $1023 \mathrm{~cm}^{-1}, 1072 \mathrm{~cm}^{-1}, 1151 \mathrm{~cm}^{-1}, 1245 \mathrm{~cm}^{-1}$ and $2166 \mathrm{~cm}^{-1}$, respectively. In addition, the peak of the asymmetric $-\mathrm{CH}_{2}$ - vibration is at 2918 $\mathrm{cm}^{-1}$. The vibration of the $\mathrm{C}=\mathrm{O}$ bonds is observed at $1719 \mathrm{~cm}^{-1}$. The peaks at $2918 \mathrm{~cm}^{-1}$ and $1450 \mathrm{~cm}^{-1}$ represent the $\mathrm{C}-\mathrm{H}$ bond. $(15,17)$.

The SEM image of the prepared membrane is shown in Figure 2. The SEM image demonstrates that the prepared membrane has a non-porous, crack-free and homogeneous structure as expected. 


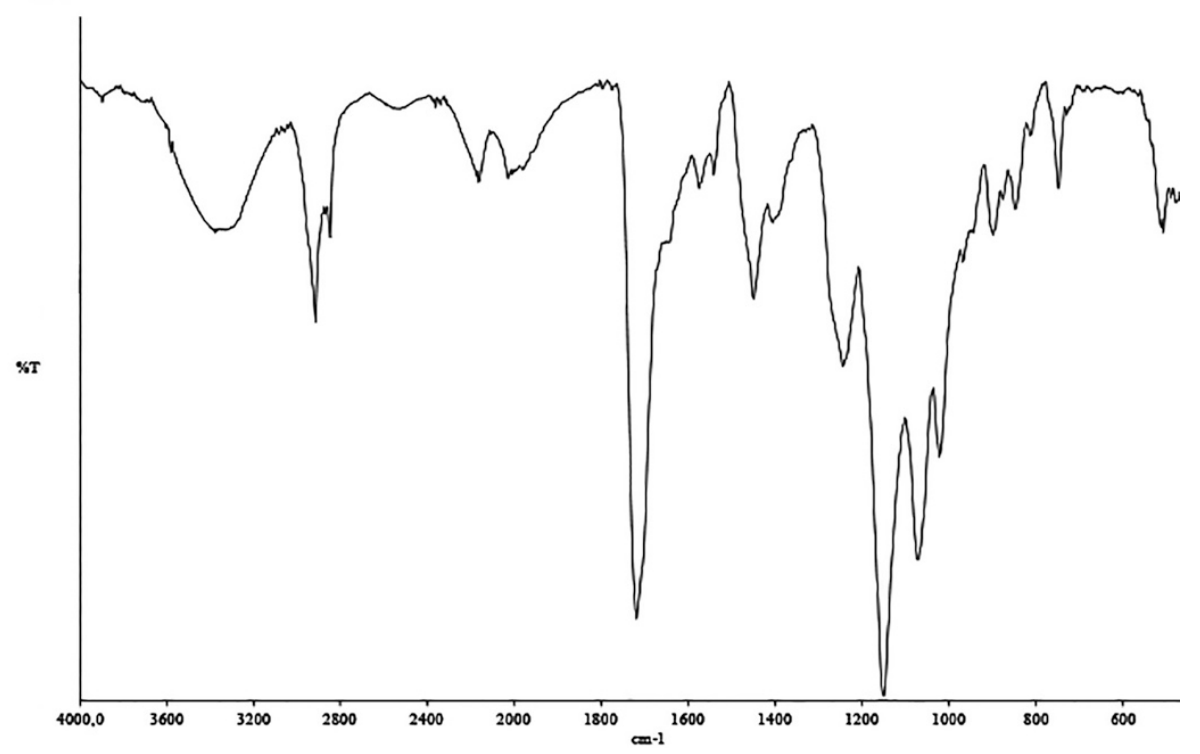

Figure 1. FTIR spectrum of polymeric membrane.

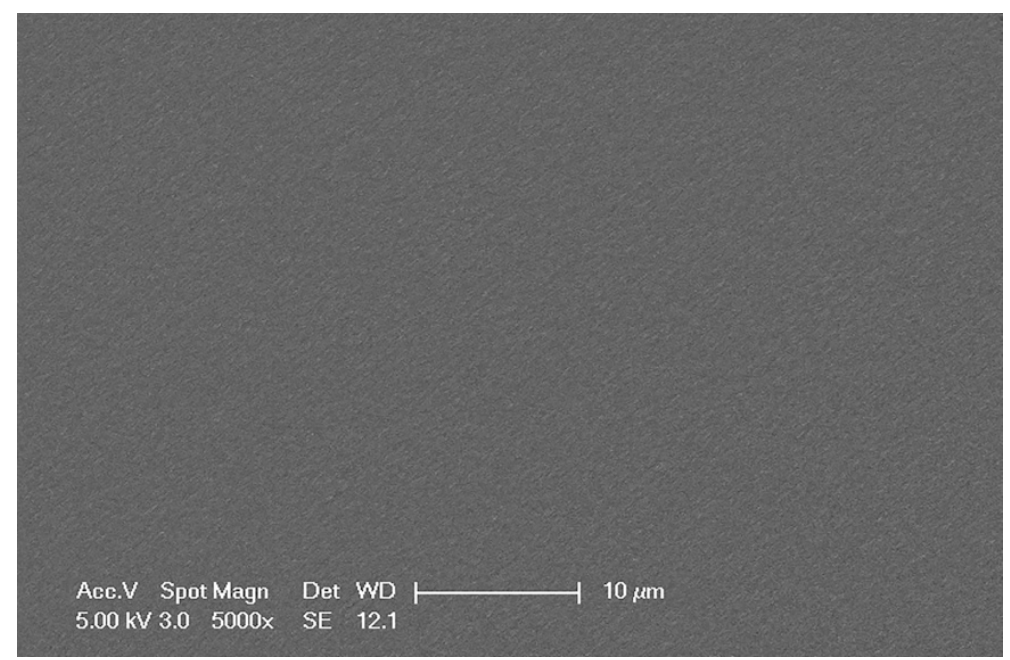

Figure 2. SEM micrograph of polymeric membrane at 5000x magnification.

\section{Spectral characterization studies}

In order to determine whether the polymeric membrane has a change in fluorescence intensity with $\mathrm{Cd}(\mathrm{II})$ ions, excitation and emission wavelength scans were performed in the absence and presence of $8.90 \times 10^{-9} \mathrm{~mol} \mathrm{~L}^{-1} \mathrm{Cd}$ (II) ions. Excitation was at $374 \mathrm{~nm}$ and the emission spectra were scanned in the range of $400-600 \mathrm{~nm}$ at slit width $5 \mathrm{~nm}$ (Figure 3). The emission maximum wavelength was found to be $422 \mathrm{~nm}$. Figure 3 shows the increase in fluorescence intensity in the presence of cadmium ions. 


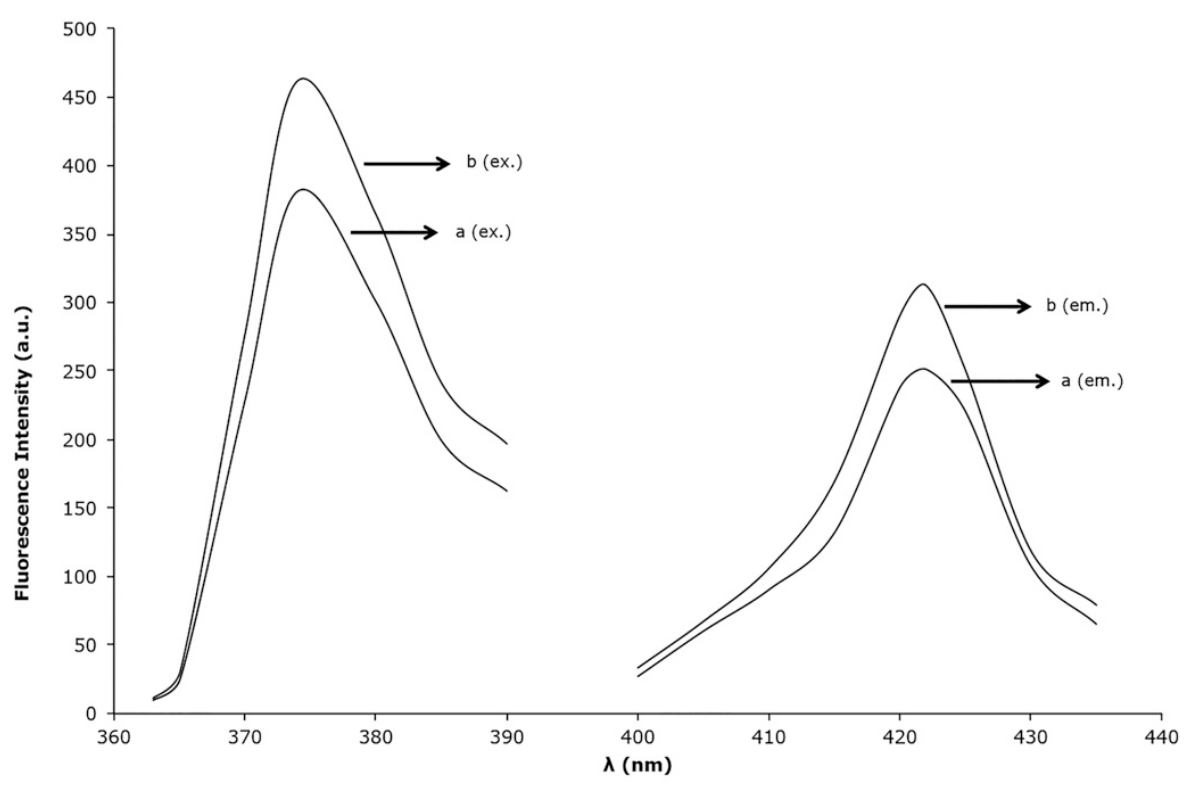

Figure 3. Excitation and emission spectra of polymeric membrane. (a) absence (line) and the (b) presence of $8.90 \times 10^{-9} \mathrm{~mol} \mathrm{~L}^{-1} \mathrm{Cd}(\mathrm{II})$ (dotted line).

\section{Optimization of the parameters for Cd(II) Determination}

In order to optimize the parameters required for the determination of cadmium ions using the developed sensor, firstly the $\mathrm{pH}$ effect was examined between the $\mathrm{pH}$ ranges of 1.0 and 11.0 in the presence of $8.90 \times 10^{-9} \mathrm{~mol} \mathrm{~L}^{-1}$ concentration of $\mathrm{Cd}(\mathrm{II})$. According to the results shown in Figure 4, the fluorescent intensity increased with increasing value of $\mathrm{pH}$ 1.0 to 5.0 , and it started to decrease at values higher than $\mathrm{pH}$ 5. The highest fluorescence intensity has been reached at $\mathrm{pH} 5.0$, therefore this $\mathrm{pH}$ value was chosen for further studies.

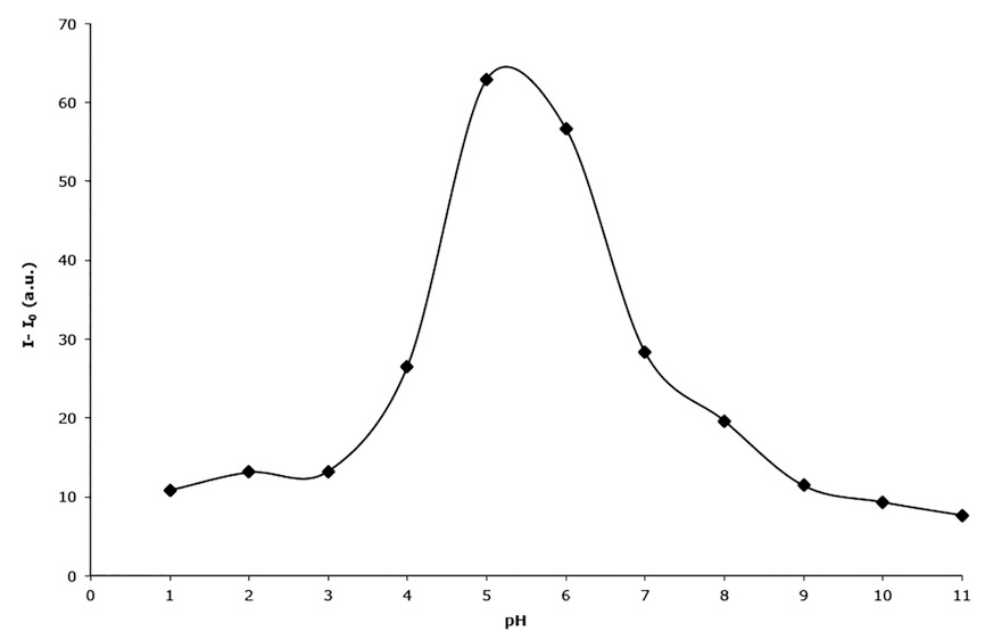

Figure 4. Fluorescence intensity change as a function of $\mathrm{pH}$ ( $\mathrm{I}_{0}$ and $\mathrm{I}$ are the fluorescence intensities before and after Cd(II) was added, respectively). 
Secondly, the effect of the response time on the fluorescence intensity was examined for 300 seconds. Figure 5 depicts the time-dependent changes in the fluorescence intensity of the sensor in the presence of $8.90 \times 10^{-9} \mathrm{~mol} \mathrm{~L}^{-1} \mathrm{Cd}$ (II) ions at $\mathrm{pH} 5.0$. As it can be seen from the Figure 5, the fluorescence intensity of the sensor did not change between 15 and 90 seconds and then it started to decrease with the increase of time. Thus, for further experiments $30 \mathrm{~s}$ was selected as analysis time.

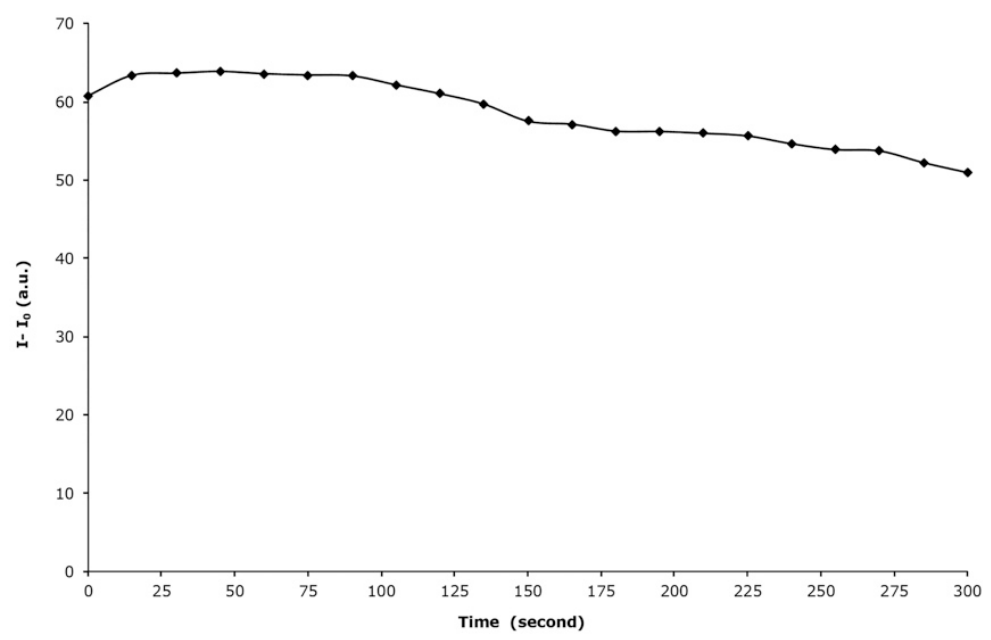

Figure 5. Time-dependent change in fluorescence intensity of the polymeric membrane $\left(\lambda_{\mathrm{ex}} / \mathrm{em}=374 \mathrm{~nm} / 422 \mathrm{~nm}\right.$; I and Io respectively indicate the states in which $\mathrm{Cd}$ (II) ions are present and absent in the solution medium).

Third, the regeneration, reversibility and reproducibility experiments of the sensor were made. After contacting the sensor membrane with the $8.90 \times 10^{-9} \mathrm{~mol} \mathrm{~L}^{-1} \mathrm{Cd}$ (II) solution, the initial fluorescence intensity was only achieved by washing for less than one minute using distilled water. For this reason, distilled water was used for the regeneration of the sensor. These results indicated that the polymeric membrane is fully reversible. A single sensor was used approximately 160 times and reproducible results were obtained with a very low standard deviation of about $2.1 \%$ (95\% confidence levels, $n=6$ ). In addition, found that the same polymeric sensor was stable for at least 250 days.

\section{Measuring range, limit of detection (LOD)}

A graphical representation of the fluorescence intensities versus the logarithm of the different Cd(II) concentrations of the developed sensor was shown in Figure 6 where Io and I are the fluorescence intensities of the membrane in the absence and presence of $\mathrm{Cd}$ (II) ions. The graph shows linearity between the concentrations of $4.45 \times 10^{-9} \mathrm{~mol} \mathrm{~L}^{-1}$ and $4.45 \times 10^{-8} \mathrm{~mol} \mathrm{~L}^{-1} \mathrm{Cd}$ (II) and was used as the calibration curve. Since this graph deviates from the linearity except for this concentration range, its values are not shown. LOD was 
found to be $6.23 \times 10^{-10} \mathrm{~mol} \mathrm{~L}^{-1}$ by calculating three times the standard deviation of the blank solution intensity $(n=6)$.

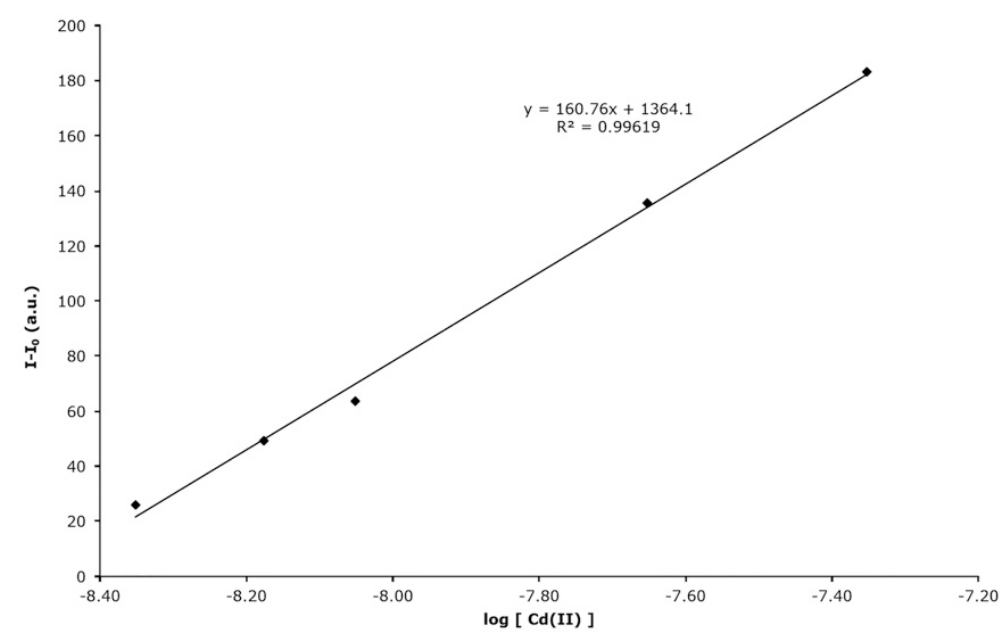

Figure 6. Calibration curve of polymeric fluorescence sensor $\left(\lambda_{\mathrm{ex}} / \mathrm{em}=374 / 422, \mathrm{pH}: 5.0\right)$.

\section{Effect of coexisting ions}

The effect of foreign ions on the fluorescence intensity was investigated in the presence of $8.90 \times 10^{-9} \mathrm{~mol} \mathrm{~L}^{-1}$ cadmium ions at $\mathrm{pH} 5.0$, with the experiment performed under the decided conditions, and the obtained results are shown in Table 1. From these results, it has been observed that even at about 1000 times of the cadmium ions, there was no effect of foreign ions on the prepared sensor intensity.

Table 1. Effect of coexisting ions on fluorescence intensity of sensor.

\begin{tabular}{lc}
\hline Species & Tolerable Limit $\left.{ }^{\mathbf{a}} \mathbf{m o l ~ L}^{-1}\right)$ \\
\hline $\mathrm{Au}(\mathrm{III})$ & $5.07 \times 10^{-6}$ \\
$\mathrm{Fe}(\mathrm{III})$ & $1.78 \times 10^{-5}$ \\
$\mathrm{Cr}(\mathrm{III})$ & $1.92 \times 10^{-5}$ \\
$\mathrm{~Pb}(\mathrm{II})$ & $4.82 \times 10^{-6}$ \\
$\mathrm{Ag}(\mathrm{I})$ & $9.25 \times 10^{-6}$ \\
$\mathrm{Co}(\mathrm{III})$ & $1.70 \times 10^{-5}$ \\
$\mathrm{Mn}(\mathrm{II})$ & $1.80 \times 10^{-5}$ \\
$\mathrm{Zn}(\mathrm{II})$ & $1.54 \times 10^{-5}$ \\
$\mathrm{Cu}(\mathrm{II})$ & $1.56 \times 10^{-5}$ \\
$\mathrm{Mg}(\mathrm{II})$ & $4.16 \times 10^{-5}$ \\
$\mathrm{Hg}(\mathrm{II})$ & $2.49 \times 10^{-6}$ \\
$\mathrm{Ni}(\mathrm{II})$ & $8.53 \times 10^{-6}$ \\
$\mathrm{Ca}(\mathrm{II})$ & $1.25 \times 10^{-5}$ \\
\hline${ }^{\mathrm{a}}$ Less than $\pm 5 \%$ relative error
\end{tabular}




\section{Real sample applications and recovery studies of developed sensor}

The $\mathrm{Cd}$ (II) concentrations in tap water and biscuits samples was calculated using the calibration graph. All experiments were conducted under optimum conditions. The results obtained from real sample applications of the prepared polymeric fluorescence sensor and the results of its recovery studies are summarized in Table 1. In addition, these results were compared with the results of analyzes carried out with GF-AAS of the same samples. The comparison showed that the developed sensor and GF-AAS results are in very good agreement with each other and the sensor can be used successfully in the determination of cadmium ions in real samples.

Table 1. Real samples applications and recovery studies of developed polymeric sensor $(n=6)$.

\begin{tabular}{lccccc}
\hline \multicolumn{1}{c}{ Sample } & $\begin{array}{c}\text { Cd(II) added } \\
\left(\mathrm{mol} \mathrm{L}^{-1}\right)\end{array}$ & $\begin{array}{c}\text { This work } \\
\left(\mathrm{mol} \mathrm{L}^{-1}\right)\end{array}$ & GF-AAS & RSD & $\begin{array}{c}\text { Recovery } \\
(\%)\end{array}$ \\
\hline Tap water & - & $(1.47 \pm 0.08) \times 10^{-8}$ & $(1.44 \pm 0.06) \times 10^{-8}$ & 1.81 & - \\
Tap water & $2.31 \times 10^{-8}$ & $(2.40 \pm 0.05) \times 10^{-8}$ & $(2.34 \pm 0.04) \times 10^{-8}$ & 2.23 & 103.8 \\
Tap water & $4.09 \times 10^{-8}$ & $(4.21 \pm 0.13) \times 10^{-8}$ & $(4.13 \pm 0.07) \times 10^{-8}$ & 1.92 & 102.9 \\
Biscuit Samples & - & $(1.02 \pm 0.06) \times 10^{-9}$ & $(1.01 \pm 0.04) \times 10^{-9}$ & 0.79 & - \\
Distillated water & - & $<$ Detection Limit & $<$ Detection Limit & - & - \\
Distillated water & $2.67 \times 10^{-8}$ & $(2.79 \pm 0.09) \times 10^{-8}$ & $(2.70 \pm 0.10) \times 10^{-8}$ & 3.26 & 104.3 \\
Distillated water & $8.90 \times 10^{-8}$ & $(9.10 \pm 0.17) \times 10^{-9}$ & $(8.96 \pm 0.07) \times 10^{-9}$ & 1.51 & 102.2 \\
\hline
\end{tabular}

\section{Comparison of the developed sensor with the other spectroscopic techniques}

Many methods have been developed for Cd(II) ions analysis and comparison of some of these methods with the developed method is shown in Table 2. As it can be seen from this table, the proposed sensor surpasses the other methods in terms of linear range and LOD value. The LOD value of the ICP-OES, ICP-AES and FAAS methods seems to be sufficient. But this value is higher than that of the developed sensor and these methods require expensive instruments. Although the analysis time of potentiometric methods seems to be the same as the method in this article, the detection limits are higher than this method. In addition, the analysis time of the spectrophotometric and spectrofluorometric methods given in the table ranges from 5 minutes to 25 minutes, which is considerably higher than the recommended sensor response time. it is also seen that it has superior performance compared to the literature methods given in Table 2. 
Table 2. Comparison of some Cd(II) analysis methods reported in the literature with the developed method.

\begin{tabular}{|c|c|c|c|c|c|c|}
\hline System & Method & $\begin{array}{l}\text { pH or } \\
\text { Medium }\end{array}$ & $\begin{array}{l}\text { Linear Range } \\
\text { (mol L-1) }\end{array}$ & $\begin{array}{c}\text { LOD } \\
\left(\mathrm{mol} \mathrm{L}^{-1}\right)\end{array}$ & $\begin{array}{l}\text { Response } \\
\text { time }\end{array}$ & Ref. \\
\hline CB-18-crown-6-GEC & DPASV & 4.5 & $\begin{array}{l}1.7 \times 10^{-6}- \\
7.03 \times 10^{-8}\end{array}$ & $2.14 \times 10^{-8}$ & $300 \mathrm{sec}$ & 4 \\
\hline Nafion-coated bismuth film electrode & DPASV & 4.5 & $\begin{array}{l}3.56 \times 10^{-8}- \\
3.20 \times 10^{-7}\end{array}$ & $1.51 \times 10^{-9}$ & $180 \mathrm{sec}$. & 5 \\
\hline Dowex Marathon $\mathrm{C}$ resin & FAAS & 3.5 & $\begin{array}{l}8.90 \times 10^{-9}- \\
8.90 \times 10^{-7}\end{array}$ & $1.16 \times 10^{-9}$ & $60 \mathrm{sec}$. & 6 \\
\hline 2,2-bipyridyl and erythrosine & ICP-OES & 4.5 & $\begin{array}{l}1.78 \times 10^{-7}- \\
3.56 \times 10^{-6}\end{array}$ & $3.56 \times 10^{-8}$ & N.M. & 7 \\
\hline $\begin{array}{l}\text { 1,13- bis (8quinolyl)-1,4,7,10,13- } \\
\text { pentaoxatridecane }\end{array}$ & $\begin{array}{l}\text { Potentiometric ion selective } \\
\text { membrane }\end{array}$ & $1.0-6.0$ & $1 \times 10^{-5}-1 \times 10^{-1}$ & $8.4 \times 10^{-6}$ & $15 \mathrm{sec}$. & 8 \\
\hline 2-nitrophenyloctyl ether & Potentiometric sensor & $4.0-7.0$ & $\begin{array}{l}2.0 \times 10^{-7}-1.0 \\
\times 10^{-2}\end{array}$ & $1.0 \times 10^{-7}$ & $15 \mathrm{sec}$. & 9 \\
\hline Tetrakis (4-nitrophenyl) porphyrin & Spectrofluorometric & in ethanol & $\begin{array}{l}1.0 \times 10^{-6} \\
1.0 \times 10^{-5}\end{array}$ & $2.46 \times 10^{-9}$ & $25 \mathrm{~min}$. & 10 \\
\hline Glyoxal-bis-(2-hydroxyanil) & Spectrofluorometric & $12.0-13.0$ & $\begin{array}{l}8.90 \times 10^{-9}- \\
8.90 \times 10^{-8}\end{array}$ & $\begin{array}{l}5.78 \times 10^{-} \\
9\end{array}$ & $10 \mathrm{~min}$. & 11 \\
\hline Alizarin Red S & Spectrophotometric & $\begin{array}{l}0.05 \mathrm{M} \text { sulfuric } \\
\text { acid }\end{array}$ & $\begin{array}{l}8.90 \times 10^{-7}- \\
3.60 \times 10^{-4}\end{array}$ & $2.67 \times 10^{-7}$ & N.M. & 12 \\
\hline p,p'-Dinitro-SYM-Diphenylcarbazid & Spectrophotometric & $11.8-12.0$ & $\begin{array}{l}4.45 \times 10^{-6} \\
5.34 \times 10^{-5}\end{array}$ & $1.16 \times 10^{-6}$ & $5 \mathrm{~min}$. & 13 \\
\hline $\begin{array}{l}\text { 1,5-bis(di-2-pyridyl) methylene } \\
\text { thiocarbohydrazide (DPTH-gel) }\end{array}$ & ICP-AES & 9.0 & $\begin{array}{l}4.45 \times 10^{-8} \\
8.90 \times 10^{-7}\end{array}$ & $9.79 \times 10^{-9}$ & $60 \mathrm{sec}$. & 14 \\
\hline$\beta-C D$ based polymeric sensor & Spectrofluorometric & $546^{5.0}$ & $\begin{array}{l}4.45 \times 10^{-9}- \\
4.45 \times 10^{-8}\end{array}$ & $\begin{array}{l}6.23 \times 10^{-} \\
10\end{array}$ & $15-90 \mathrm{sec}$ & OM \\
\hline
\end{tabular}




\section{CONCLUSION}

In this study, a reusable polymeric fluorescence sensor for the analysis of cadmium ions in water and food samples, has been developed. Parameters required for determination such as $\mathrm{pH}$, measurement range, selectivity, precision, response time, and reproducibility were also systematically examined. Fluorescence spectra showed that the excitation/emission maxima of the sensor were at 374/422 nm, respectively. Cd(II) ions with developed sensor can be determined in a short period of about 30 seconds. The prepared sensor shows a linear response for $\mathrm{Cd}$ (II) ions at a measurement range of $4.45 \times 10^{-9}$ to $4.45 \times 10^{-8} \mathrm{~mol} \mathrm{~L}^{-1}$ with a detection limit of $6.23 \times 10^{-10} \mathrm{~mol} \mathrm{~L}^{-1}$ at $\mathrm{pH} 5$. The results show that the developed sensor can be successfully used to the detection of $\mathrm{Cd}$ (II) ions in various matrices.

\section{ACKNOWLEDGMENTS}

This work was supported by Marmara University, Commission of Scientific Research Project (M.Ü. BAPKO) under grant FEN-D-090217-0068.

\section{REFERENCES}

1. Robards K, Worsfold P. Cadmium: toxicology and analysis. A review. The Analyst. $1991 ; 116(6): 549$.

2. Sherlock JC. Cadmium in foods and the diet. Experientia. 1984 Feb;40(2):152-6.

3. Parker SP, McGraw-Hill, inc, editors. McGraw-Hill encyclopedia of engineering. 2nd ed. New York: McGraw-Hill; 1993. 1414 p.

4. Serrano N, González-Calabuig A, del Valle M. Crown ether-modified electrodes for the simultaneous stripping voltammetric determination of $\mathrm{Cd}(\mathrm{II}), \mathrm{Pb}$ (II) and $\mathrm{Cu}$ (II). Talanta. 2015 Jun; 138:130-7.

5. Xu H, Zeng L, Huang D, Xian Y, Jin L. A Nafion-coated bismuth film electrode for the determination of heavy metals in vegetable using differential pulse anodic stripping voltammetry: An alternative to mercury-based electrodes. Food Chemistry. 2008 Aug;109(4):834-9.

6. Daşbaşı T, Saçmacı Ş, Ülgen A, Kartal Ş. A solid phase extraction procedure for the determination of $\mathrm{Cd}(\mathrm{II})$ and $\mathrm{Pb}$ (II) ions in food and water samples by flame atomic absorption spectrometry. Food Chemistry. 2015 May; 174:591-6.

7. Feist B, Mikula B, Pytlakowska K, Puzio B, Buhl F. Determination of heavy metals by ICP-OES and F-AAS after preconcentration with 2,2'-bipyridyl and erythrosine. Journal of Hazardous Materials. 2008 Apr;152(3):1122-9.

8. Ghaemi A, Tavakkoli H, Mombeni T. Fabrication of a highly selective cadmium (II) sensor based on 1,13-bis(8-quinolyl)-1,4,7,10,13-pentaoxatridecane as a supramolecular ionophore. Materials Science and Engineering: C. 2014 May;38:186-91.

9. Rezvani Ivari SA, Darroudi A, Arbab Zavar MH, Zohuri G, Ashraf N. Ion imprinted polymer based potentiometric sensor for the trace determination of Cadmium (II) ions. Arabian Journal of Chemistry. 2017 Feb;10:S864-9. 
10. Khani R, Ghiamati E, Boroujerdi R, Rezaeifard A, Zaryabi MH. A new and highly selective turn-on fluorescent sensor with fast response time for the monitoring of cadmium ions in cosmetic, and health product samples. Spectrochimica Acta Part A: Molecular and Biomolecular Spectroscopy. 2016 Jun;163:120-6.

11. Dong Y, Gai K. The application of glyoxal-bis-(2-hydroxyanil) to the determination of trace amounts of cadmium by spectrofluorimetry. Journal of the Brazilian Chemical Society. 2006 Feb;17(1):135-8.

12. Ullah M, Haque ME. Spectrophotometric Determination of Toxic Elements (Cadmium) in Aqueous Media. Journal of Chemical Engineering [Internet]. 2011 Mar 10 [cited 2017 Apr 11];25(0). Available from: http://www.banglajol.info/index.php/JCE/article/view/7233

13. Bulgariu L, Bulgariu D, Sârghie I. Spectrophotometric Determination of Cadmium(II) Using p, $\mathrm{p}^{\prime}$ Dinitro-SYM-Diphenylcarbazid in Aqueous Solutions. Analytical Letters. 2005 Nov;38(14):2365-75.

14. Zougagh M. Determination of cadmium in water by ICP-AES with on-line adsorption preconcentration using DPTH-gel and TS-gel microcolumns. Talanta. 2002 Mar 11;56(4):753-61.

15. Constantin M, Bucatariu S, Ascenzi P, Simionescu BC, Fundueanu G. Poly (NIPAAm-co- $\beta$ cyclodextrin) microgels with drug hosting and temperature-dependent delivery properties. Reactive and Functional Polymers. 2014;84:1-9.

16. Li L, ErLong L, JiangHui L, JinHua W, XiaoLin L, Feng L, et al. Foodstuffs-determination of elements and their chemical species-general considerations and specific requirements-an translation from EN 13804: 2013. Journal of Food Safety and Quality. 2014;5(10):3349-3355.

17. Demir S, Kahraman MV, Bora N, Kayaman Apohan N, Ogan A. Preparation, characterization, and drug release properties of poly(2-hydroxyethyl methacrylate) hydrogels having $\beta$-cyclodextrin functionality. Journal of Applied Polymer Science. 2008 Jul 15;109(2):1360-8. 